\title{
Crustal structure of Guadeloupe Islands and the Lesser Antilles Arc from a new gravity and magnetic synthesis
}

\author{
Gailler L., Martelet G., Thinon I., Bouchot V., Lebrun J.-F., Munch P.
}

Corresponding author: lydiegailler@hotmail.fr

Guadeloupe Island (West French Indies) is one of the twenty islands that compose the Lesser Antilles Arc, which results from the subduction of the Atlantic Ocean plate beneath the Caribbean one. The island lies in a complex volcano-tectonic system and the need to understand its geological context has led to numerous on- and offshore geophysical investigations. This work presents the compilation and processing of available, on-land, airborne and marine, gravity and magnetic data acquired during the last 40 years on Guadeloupe Islands and at the scale of the Lesser Antilles Arc. The overall dataset provides new Bouguer and reduced to the pole magnetic anomaly maps at the highest achievable resolution. Regionally, the main central negative gravity trend of the arc allows defining two subsident areas. The first one is parallel to the arc direction $\left(\sim \mathrm{N} 160^{\circ} \mathrm{E}\right)$ to the north, whereas the second unexpected southern one is oriented parallel to oceanic ridges $\left(\mathrm{N} 130^{\circ} \mathrm{E}\right)$. Along the Outer Arc, the long wavelength positive anomaly is interpreted, at least along the Karukera Spur, as an up-rise of the volcanic basement in agreement with the seismic studies. To the NE of Guadeloupe, the detailed analysis of the geophysical anomalies outlines a series of structural discontinuities consistent with the main bathymetric morphologies, and in continuity of the main fault systems already reported in this area. Based on geophysical evidences, this large scale deformation and faulting of the Outer Arc presumably primarily affects the Atlantic subducting plate and secondarily deforms the upper Caribbean plate and the accretion prism. At the scale of Guadeloupe Island, joined gravity and magnetic modeling has been initiated based on existing interpretation of old seismic refraction profiles, with a general structure in three main layers. According to our geophysical anomalies, additional local structures are also modeled in agreement with geological observations: $i$ ) the gravity and magnetic signals confirm an up-rise of the volcanic basement below the limestone platforms outcropping on Grande-Terre Island ; ii) the ancient volcanic complexes of Basse-Terre Island are modeled with high density and reverse magnetized formations; iii) the recent volcanic centre is associated with formations consistent with the low measured density and the underlying hydrothermal system. The EW models coherently image a NNW-SSE depression structure in half-graben beneath Basse-Terre Island, its western scarp following the arc direction in agreement with bathymetric and seismic studies to the north of the island. The so-defined depressed area, and particularly its opening in half-graben toward the SW, is interpreted as the present-day front of deformation of the upper plate associated with the recent volcanic activity on and around Guadeloupe. Based on this regional deformation model, perspectives are given for further integrated investigation of key targets to address the internal structure and evolution of the Lesser Antilles Arc and Guadeloupe volcanic system.

Keywords: Lesser Antilles Arc; Guadeloupe Island; geophysical surveys; geophysical data synthesis; magnetic and gravity anomalies; modeling; seismic profiles; subsidence, deformation, crustal structures 